\title{
Movimento do protoplasma nos pêlos internos do tubo da corola de Allamanda cathartica, Linn.
}

\author{
WALTER RADAMÉS ACCORSI \\ Prof. Cat. de Botânica Geral e Descritiva \\ E. S. A. "Luiz de Queiroz" U. S. P. - Piracicaba
}

INDICE

$\begin{array}{llllllllll}1 & \text { - Introdução } \ldots & \ldots & \ldots & \ldots & \ldots & \ldots & \ldots & \ldots & \ldots\end{array}$

2 - Material e método .... ... ................. 23



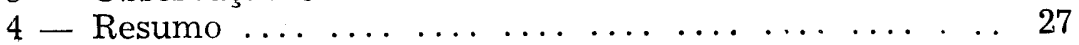

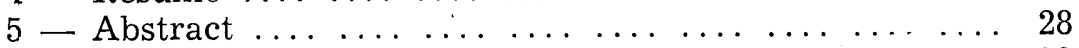

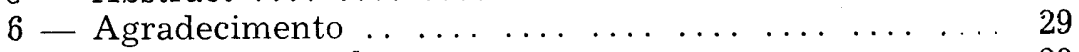

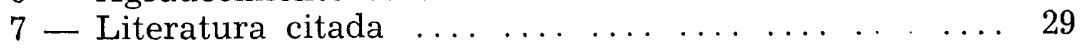




\section{INTRODUÇÃO}

Segundo GOLA, NEGRI e CAPPELLETTI (1951), n movimento do citoplasma foi observado e pela primeira vez descrito pelo abade italiano Bonnaventura Corti, nas células de Chara, em 1774, e denominado circulação ou rotação protoplas.mática. GUILLIERMOND (1941) designa o fenômeno cun. o têrmo ciclose.

Minúsculas granulações ou gotículas de material lipóide deslocam-se ao longo dos cordões citoplasmáticos, permitiridc apreciar a intensidade do movimento, o qual é assaz irregular, pois segue diverșas direções e possui velocidades diferenies.

Para GOLA, NEGRI e CAPPELLETTI, os movimentus dessa natureza resultam das incessantes modificações físicoquímicas de que o citoplasma é a sede, como deslocações mole culares devido a diferentes velocidades de trocas no metab. lismo e, em particular, nos fenômenos respiratórios. Os fato. res luz, temperatura, correntes elétricas, mudança do $\mathrm{pH}$ do suco celular ou do meio ambiente influem na circulação do protoplasma.

Além dos fatores acima, traços de cobre ou concentrações fracas de cloreto de bário ou de estrôncio, intensificam sobremodo, consoante SEIFRIZ (1936), a velocidade do movimento protoplasmático nas células da fôlha de Elodea.

A intensidade de tais movimentos serve para estabelecerse o grau de vitalidade de uma célula ou para a avaliação dos efeitos dos estímulos.

Êsse curiosíssimo fenômeno, de acôrdo com as citações clássicas, pode ser fàcilmente observado em células grandes, com enormes vacúolos, ricos de água, como as células de Chara, Nitella (Charophyta), Spirogyra, nas túnicas de Allium, na epiderme de Iris, nas fôlhas de Elodea canadensis, nos pêlos estaminais de Tradescantia, nos de Chelidonium majus, nos pêlos dos caules novos de Cucurbita pepo, nos pêlos absorventes das raízes novas de Hydrocharis Morsus-Ranae, nas fôlhas de Vallisneria spiralis, no plasmódio dos mixomicetos, nas hifas dos fungos, etc..

Depreende-se, do exposto, que a ocorrência do movimento do protoplasma, no reino vegetal, é bastante ampla, encontrando-se em células pertencentes a organismos dos mais diversos graus evolutivos, desde os mixomicetos até aos vegetais de alta diferenciação morfológica e fisiológica. 
Na 3a. Reunião da Seção de São Paulo da Sociedade Botânica do Brasil, realizada em Piracicaba, em 20 de abril de 1951, fizemos uma demonstração aos botânicos presentes do mo- vimento do protoplasma nos pêlos da corola de Allamanda cathartica. Posteriormente, em 1952, tivemos oportunidade de mencionar, outra vez, o mesmo fato, na aula inaugural do curso de agronomia (ACCORSI, 1952).

\section{MATERIAL E MÉTODO}

Condensamos, neste trabalho, dados e observações que pudemos coligir em tôrno do movimento do protoplasma exibido pelos pêlos que guarnecem a face interna do tubo da corola de Allamanda calhartica, Linn. - a conhecida "alamanda-de-flirgrande". Como dissemos, os pêlos reunem-se em feixes que, por sua vez, se inserem em frente e um pouco acima de cada estame, de tal forma que o conjunto dêles constiıui uma cúpula protetora das anteras.

Nas flôres bem desabrochadas os pêlos podem alcançar até $4 \mathrm{~mm}$ de comprimento. São hialinos, unicelulares, em regra cilíndricos e um tanto afilados na extremidade. Alguns há, entre êles, que são sinuosos. Numerosas incrustações pequenas, de composição cerácea, elípticas, circulares e às vêzes irregulares, distribuem-se pela membrana e oferecem o aspecto de calota quando vistas em corte ótico.

A membrana dessecada dos pêlos, quando examinada com grande aumento, mostra-se finamente esculturada por estrias longitudinais, retilíneas ou um tanto curvilíneas, de comprimento variável. Umas são simples, outras ramificadas por dicotomia. Em certos trechos, ocorrem estrias transversais, bem mais espaçadas que as longitudinais e a membrana se apresenta quadriculada.

Abaixo da inserção dos estames, o tubo da corola exibe pêlos esparsos, porém menores em número e tamanho que os dos feixes acima dos estames.

A técnica usada para a extração dos pêlos, quer de botões ou de flôres bem abertas, é simples e se resume nas seguintes operações : 




Fig. 1 - Corte longitudinal da flor de Allamanda cathartica. Aumento x 1. a) tubo da corola; b) pêlo (forma feixes); c) estame (antera); d) estigma; f) estilete. (Original) 
1 - Com uma tezourinha, escalpelo, agulha-lanceolada ou lâmina de barbear, remove-se a porção da corola acima do tubo, de modo a expôr o cône de pêlos, que se compõe, como sabemos, de cinco fascículos de pêlos.

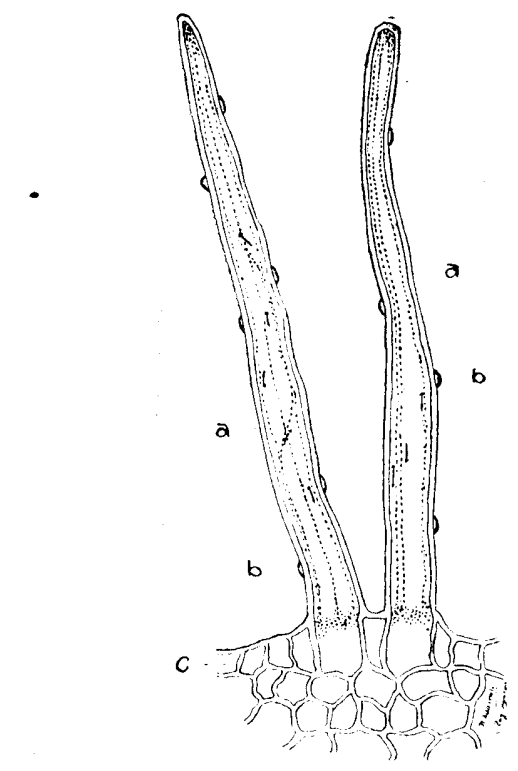

Fig. 2 - Pêlos aumentados $32,5 \mathrm{x}$. a) parede do pêlo; b) placos de cêra. As setas indicam a direção do movimento do protoplasma (microssômios). (Original).

2 - Divide-se, a seguir, longitudinalmente o tubo da corola em cinco partes. Retiram-se as anteras com o escalpelo, deixando apenas os fascículos de pêlos.

3 - Para eliminar a maior parte do ar retido entre os pêlos, a fim de não prejudicar o exame ao microscópio (forma- 
ção de bôlhas), mergulham-se os fragmentos obtidos em água ligeiramente aquecida, durante algum tempo. Pode-se, também, encher prèviamente o tubo da corola com água morna, conseguindo-se os mesmos resultados.

4 - Umedecidos os pêlos e eliminado o ar, com o auxílio de um escalpelo, agulha lanceolada ou lâmina de barbear, cortamse delgadas fatias do tubo da corola, em sentido longitudinal, de tal forma que cada secção contenha reduzido número de linhas de pêlos. Na realização desta operação, que deve ser feita ao binocular estereoscópico, evitar qualquer traumatismo nos pêlos, a fim de não paralisar o movimento do protoplasma.

5 - A montagem do material na lâmina é feita em água destilada, na qual podern ser postas algumas gôtas de vermelho neutro, a 1/1000, colorindo-se, assim, os pêlos, que são hialinos. Experimentamos, com êxito, a montagem em vaselina líquida, que elimina prontamente o ar e dissolve as placas que incrustam a parede. O único inconveniente no uso da vaselina líquida é que se produz certa refringência ao redor dos pêlos, o que dificulta, em parte, o exame do movimento. Obtivemos, por outro lado, resultados satisfatórios empregando, na montagem, álcool a $10^{\circ}$, que expulsa parte do ar e não prejudica o movimento do protoplasma.

\section{OBSERVAÇÃO E DISCUSSÃO}

LUBIMENKO (1927) classifica o movimento do protoplasma em dois tipos: giratório, quando as camadas protoplasmáticas parecem deslocar-se sob a membrana e ondulatório, quando o protoplasma se move por pequenas ondas, ao longo dos cordões citoplasmáticos que atravessam a célula de um ponto a outro. $O$ primeiro ocorre nas células com vacúolo grande e central, reduzindo-se o citoplasma a uma faixa parietal. O segundo verifica-se nas células com numerosos vacúolos esparsos, de sorte que o protoplasma, além de forrar a membrana, apresenta, ainda, cordões que atravessam o campo celular em várias direções.

Das observações feitas nos pêlos de Allamanda, concluimos que o movimento protoplasmático, conforme o trecho considerado, ora é giratório, ora é ondulatório e isso devido, mui 
provàvelmente, ao comprimento e à largura dos pêlos bem como à presença de vários vacúolos. Apreciável é a quantidade de microssômios que se deslocam e é muito comum vermos correntes paralelas e em sentido contrário, ao longo da pareds, num percurso relativamente extenso. De quando em vez, essas correntes cruzam-se e os microssômios aglomeram-se de tal forma que o trânsito se interrompe, por certo tempo. Não raro, verificam-se desvios na direção, passando a corrente de uma a outra margem da célula.

Confrontando-se na mesma lâmina pêlos de Allamanda (unicelulares) com os de Tradescantia (pluricelulares), temos a impressão de que o movimento protoplasmático é mais rápido em Tradescantia. Contudo, os microssômios de Allamanda são mais numerosos e maiores, tornando o movimento mais nítidu e mais intenso. Constatámos, também, que o protoplasma das células da epiderme do filête dos estames de Tradescantia possui movimento giratório, principalmente na região colorida pela antocianina, contrastando, por conseguinte, com o das células dos pêlos, que é do tipo ondulatório.

Os pêlos dos botões dẹsenvolvidos de Allamanda são mais lisos, isto é, com poucas incrustações de cêra e de conformação mais uniforme. Nos botões bem novos os pêlos são curtos, cilindro-cônicos e com paredes lisas. Em ambos os tipos de pêlos, o movimento do protoplasma é bem visível e intenso.

Examinamos, com o mesmo propósito, os pêlos esparsos do tubo da corola de Plumeria lutea (apocinácea), a conhecida “jasmim-manga", os quais, em comparação com os de Allamanda são mais curtos e finos, cilíndricos e de paredes mamilosas Verificamos que o movimento do protoplasma é pouco intenso e pequena a quantidade de microssômios.

Pretendemos, de futuro, relatar a existência de outros exemplos de movimento citoplasmático que encontramos em Ctenanthe, Zea tunicata, Stephanotis floribunda, etc.. Em Stephanotis o movimento é visível nos pêlos esparsos pela base do tubo da corola, mas é pouco intenso.

\section{RESUMO}

Apreciamos, neste trabalho, mais um exemplo de movimento do protoplasma nos pêlos da corola de Allamanda cathartica - vulgarmente chamada "dedal-de-dama", ou "Ala- 
manda-de-flor-grande", e que se reunem em cinco feixes cônicos, dispostos em frente e um pouco acima dos estames.

A técnica empregada na extração dos pêlos destinados ao exame microscópico pode ser resumida nas seguintes operações :

1 - Eliminar a maior porção da corola, até o nível do cône de pêlos.

2 - Dividir o tubo da corola em cinco partes, que são colocadas em água morna para a expulsão do ar retido entre os pêlos. Pode-se, também, encher prèviamente o tubo da corola com água morna, antes da operação número 1.

3 - Cortar, ao binocular estereoscópico, com um escalpelo ou lâmina de barbear, fatias delgadas do tubo da corola, contendo reduzido número de linhas de pêlos. Evitar traumatizemse os pêlos, a fim de não paralisar o movimento do protoplasma.

4 - Montagem do material em água destilada, vaselina líquida (as placas de cêra dissolvem-se e o ar é eliminado prontamente. $O$ inconveniente é a formação de certa refringência ao redor do pêlo) ou álcool a $10^{\circ}$.

Do estudo feito concluimos que o movimento se manifesta com certa intensidade e conta com apreciável quantidade de microssômios, podendo ser classificado ora como giratório, ora como ondulatório e isso conforme o trecho do pêlo considerado. Essa variação deve relacionar-se, provàvelmente, com as dimensões dos pêlos e com o número de vacúolos. De quando em vez, as correntes protoplasmáticas chocam-se e os microssômios aglomeram-se de tal forma que o trânsito celular se interrompe momentâneamente.

\section{ABSTRACT}

A new example of protoplasmic streaming occuring in the hairs attached to the inner wall and just above the anthers of corolla tube of Allamanda cathartica is described. There are five fascicles of hyalin and unicellular hairs, one for each sta- 
men; they are united together, forming a conical protection over the anthers.

The following procedure is recommended for microscopical examinations : it is necessary to remove most of the corolla as far as the level of the cone of hairs, and then the tube is divided in to five parts; under stereoscopic lupe, thin tube sections are obtained with a scalpel, lanceolated needle or razor blade, and the sections with a few hairs are mounted in water or liquid vaseline. In order to obtain good slides it is important to remove the air kept among the hairs with warm water, ten per cent ethyl alccohl or liquid vaseline. The only inconvenient presented by the use of liquid vaseline is some refringece around the hairs.

The protoplasmic streamings are very active, but currents have not always the same course along the hairs; many time they change their directions and the cytoplasmic flows may be rapid or evenrushy in a protoplasmic strands.

The bodies called "microsomes", which are suspended in the protoplasm, in most cases are carried along more or less rapidly by the currents.

The observed movements belong to the gyratory, and ondulatory types.

\section{AGRADECIMENTO}

Agradecemos à Dra. Myrthes A. Adamoli de Barros a feitura dos desenhos que ilustram êste trabalho.

\section{LITERATURA CITADA}

1-ACCORSI, W. R., 1951 - Movimento do Protoplasma nos Pêlos Internos do Tubo da Corola de Allamanda cathartica (Resumo apresentado à $3 a$. Reunião da Secção de S. Paulo da S. Botânica do Brasil, em Piracicaba). 
$2-\longrightarrow, 1952$ - Os Fenômenos de Movimento no Reino Vegetal. Aula Inaugural de 1952. Anais da E. S. A. "Luiz de Queiroz". Vol. 9, 1952.

3 - GOLA, NEGRI, CAPPELLETTI, 1951 - Trattato Di Botanica. 3a. Edizione - Unione Tirpografico-Editrice Torinese. Torino.

4-GUILliERMOND, A., 1941 - The Cytoplasm of the Plant Cell. Published by the Chronica Botanica Company, Waltham, Mass., U.S.A..

5-LUBIMENKO, V., 1927 - Traité de Botanique Générale. Traduit du Russe par Mlle. Anna Joukov, 2 vols. Gauthier-Villars et Cie., Editeurs. Paris.

6 - SEIFRIZ, W., 1936 - Protoplasm. First Edition, Third Impression. Mc Graw-Hill Book Company, Inc. New York and London. 